\title{
Covid -19'un Borsa İstanbul Üzerindeki Etkisi: Bir ARDL Sınır Testi Modeli*
}

\section{ÖZET}

Bir bütün olarak değerlendirildiğinde koronavirüsün (COVID-19) hem sağllk hem de ekonomi üzerindeki şok etkisinin, uzun vadede ne tür sonuçlar doğuracă̆ tam olarak bilinmemektedir. 2008 küresel ekonomik krizi ile karşılaştırıldı̆̆ında ekonomiye etkilerinin daha fazla olduğu görülmektedir. Bu amaçla çalışmada, koronavirüs salgınının finansal piyasalar üzerindeki etkisi Dağıtılmış Gecikmeli Otoregresif Sinır Testi (ARDL- Autoregressive Distributed Lag Bound Test) yöntemi kullanılarak analiz edilmiştir. Bağımsız değişken olarak günlük doğrulanmış COVID-19 pozitif vaka sayıları ve bağıml değişken olarak Borsa İstanbul (BIST) toplam işlem hacmi verileri kullanılmıştır. Türkiye'de ilk pozitif vakanın görüldügü 11 Mart 2020 tarihi, analiz dönemi başlangıcı olarak belirlenmistir. Alınan sıkı tedbirlerin ardından normalleşme adımlarının atıldiğg 16 Haziran 2020 tarihine kadar olan süreç, analize dahil edilmiştir. Çalışma sonucunda, COVID-19'un borsa işlem hacmi üzerinde kisa vadede negatif yönde ve anlaml bir etkisi olduğu, uzun vadede ise pozitif yönde ve anlamlı bir etkisi olduğu belirlenmiştir.

Anahtar Kelimeler: COVID-19, Borsa İstanbul, ARDL Sinır Testi

JEL Sinıflandırması: I10, G15, C32, O53

\section{The Effect of COVID-19 on Borsa Istanbul: An ARDL Bound Test Model}

\section{ABSTRACT}

The long run effect of the coronavirus (COVID-19) pandemic on both human health and the economy is unknown. Compared to the 2008 global economic crisis, it has had greater effects on the economy. This study analyzes the effect of the COVID-19 pandemic on Borsa Istanbul (BIST) by using the autoregressive distributed lag $(A R D L)$ bound test. The study used the daily number of confirmed COVID-19 cases as the independent variable and BIST's total trading volume as the dependent variable. The analysis period is from March 11, 2020, the date of the first confirmed case in Turkey, to June 16, 2020, the date of the commencement of the normalization steps after the strict measures were imposed. The result shows that COVID-19 had a significant negative effect on the stock market's trading volume in the short-run and a significant positive effect in the long-run.

Keywords: COV-19, Borsa Istanbul, ARDL Bound Testing

Jel Classification: I10, G15, C32, O53

\footnotetext{
* Makale Gönderim Tarihi: 05.10.2020, Makale Kabul Tarihi: 27.11.2020, Makale Türü: Nicel Araştırma ** . Öğr. Gör. Dr. Muğla Sitkı Koçman Üniversitesi, Fethiye A.S.M.K. Meslek Yüksekokulu, fcontuk@mu.edu.tr, ORCID:0000-0003-3757-2697
} 


\section{GİRiş}

Aralık 2019' da Çin'in Hubei eyaletine bağlı Wuhan şehrinde başlayan ve hızla yayılarak tüm dünyayı etkisi altına alan Koronavirüs (Covid-19) salgını, 11 Mart 2020 günü Dünya Sağlık Örgütü (WHO) tarafından pandemi olarak ilan edilmiş ve önleyici tedbirler alınması için tavsiyeler yayınlanmıştır. 16 Haziran 2020 tarihine kadar 4 ay gibi kısa bir sürede, dünya çapında bildirilen yaklaşık 8 milyon Covid-19 vakası vardır ve yaklaşık 435,000 ölüm rapor edilmiştir (WHO,2020). Pandemi sadece küresel bir acil sağlık durumu değil, aynı zamanda önemli bir küresel ekonomik gerileme tehlikesi oluşturmuştur. Pek çok ülke görünmeyen salgınla mücadele etmek için katı karantina politikaları benimsediğinden, ekonomik faaliyetler aniden durmuştur. Pandemi başlangıcında, ülkeler arasındaki ulaşımın sınırlandırılması ve devamında tamamen durdurulması küresel ekonomik faaliyetleri yavaşlatmıştır.

Koronavirüs salgınının etkilerinin boyutu henüz bilinmemekle birlikte, ekonomik faaliyetler üzerinde önemli etkileri olduğu görülmektedir. Mart 2020'nin sonunda, dünyanın dört bir yanında 100 'den fazla ülke kısmi veya tam tecritleri başlatmıştır. Küresel ölçekte yapılan kültürel ve destekleyici etkinlikler askıya alınmıştır. Ülkeler vaka sayılarının ve ölümlerin gün geçtikçe artmasıyla birlikte ulusal düzeyde hastalığı kontrol altına almak için sosyal mesafe, sokağa çıkma yasağı, şüpheli vakaların test edilmesi ve karantinaya alınması, doğrulanmış vakaların tedavi edilmesine yönelik yatırımlar gibi acil durum önlemleri almışlardır. Ancak bu tedbirler ekonomi alanındaki endişeleri arttırmıştır. Bu endişelerle birlikte birçok ülkenin hükümetleri, maliye bakanlıklarından merkez bankalarına kadar, ekonomik zararı kontrol altına almak için destek ve teşvik paketleri açıklamışlardır (Ashraf,2020:2)

Çin ekonomisinin üretim kesintileriyle yavaşlamasıyla, küresel tedarik zincirlerinin işleyişi sekteye uğramış ve Çin'den gelen girdilere bağlı olarak, büyüklüklerine bakılmaksızın dünya çapında şirketler, üretimde daralmalar yaşamaya başlamıştır. En önemlisi, tüketiciler ve firmalar arasında oluşan panik olağan tüketim kalıplarını bozmuş ve pazar anormallikleri yaratmıştır. Küresel finans piyasaları da değişikliklere duyarlı hale gelmiş ve küresel hisse senedi endeksleri düşmüştür. Korona virüsünün yayılması, dünya çapında hisse senedi fiyatlarında düşüşlere, hisse senedi fiyatı oynaklığında artışlara, nominal faiz oranlarında düşüşlere ve reel GSYİH' ye yansıyan reel ekonomik faaliyette daralmalara yol açmıştır (Kotishwar,2020:2). Kısacası COVID-19 kaynaklı ekonomik kayıplar küresel borsaları da etkilemiştir. Başta finans piyasaları olmak üzere çeşitli ülkelerin ekonomik ve finansal sistemlerinde aksamalara neden olan Covid-19'un yayılmasıyla küresel sağlık krizlerinin faturası ağırlaşmıştır. Şu anda virüsün bir bütün olarak borsa üzerinde uzun vadeli etkileri tam olarak bilinmemekle birlikte borsalar süreç içinde spekülatif hareketlere maruz kalmışlardır (Yan vd. 2020:1).Yatırımcıların duyguları borsaları önemli ölçüde etkiler. Piyasa yukarı yönlü seyrederken ve algılanan risk daha az olduğunda, yatırımcı daha iyimser davranır. Piyasa düşüş eğilimi gösterdiğinde, yatırımcıların duyguları nispeten kötümser hale gelir ve yatırımcılar, bir canlanma başlayana kadar piyasaya girmek için bekleme eğiliminde olacaktır. $\mathrm{Bu}$ tür durumlar, kısa vadeli yatırımcıların aşırı tepkisine yol açar. Küreselleşme, ekonomileri dünya çapında birbirine bağlamış ve son yıllarda küresel finans piyasalarının karşılıklı bağımlılığını artırmıştır. Küresel hisse senedi piyasaları arasındaki bu artan karşılıklı bağımlılık, küresel yatırımcıların varlık tahsisi ve ekonomiler üzerindeki kararlarının yanı sıra ekonomik politikalar üzerinde öneli bir etkiye sahiptir (Liu, 2020:2). 
Koronavirüs salgını, Türkiye'nin en fazla ticari ilişki içinde olduğu Avrupa ülkeleri başta olmak üzere dünya çapında hızla yayılmış ve 2020 Mart ayından itibaren ülkemizde iktisadi faaliyetleri sınırlamaya başlamıştır. Salgının iktisadi faaliyetlerdeki etkisi Nisan ayında derinleşmiştir. Salgın bazı sektörlerin yavaşlamasına bazılarının ise durma noktalarına gelmesine neden olmuştur. Bu durum reel sektör üzerinde baskı oluşturmuş ve ekonomideki ihtiyati likidite talebi artmıştır. Birçok ülkede olduğu gibi ülkemizde de politika yapıcılar salgının etkilerini en aza indirmek ve olumsuz yansımalarını ortadan kaldırmak için kapsamlı politika adımları atmıştır (Finansal İstikrar Raporu, 2020). Çalışmada, küresel finans piyasalarında geniş kapsamlı ve kayda değer şok dalgalarına neden olan koronavirüsün, ülkemizdeki iktisadi faaliyetler üzerindeki olumsuz etkileri dikkate alındığında, finansal piyasalara olan etkisinin belirlenmesi amaçlanmıştır. Bu amaçla günlük doğrulanmış COVID19 onaylı vakaların ve BIST toplam işlem hacminin doğal logaritmaları alınarak, aradaki ilişki ARDL sınır testi ile analiz edilmiştir.

\section{LITERATÜR}

Öztürk vd. (2020), Covid-19 salgınının Türkiye'deki finansal piyasalar üzerindeki etkisini sabit etkiler yöntemiyle incelemişlerdir. Çalışma sonucunda sektörlerin, Avrupa ve dünyadaki vakalardan daha çok Türkiye'deki vaka sayılarından etkilendiğini belirlemişlerdir. Salgından en çok metal ürünleri ve makine sektörünün etkilendiği belirlenmiştir. Ekonomide yaşanan durgunluğa rağmen zorunlu ihtiyaçları karşılayan sektörlerin ve gayrimenkul sektörünün en az etkilenen sektörler olduğu tespit edilmiştir.

Ashraf (2020), borsaların COVID-19 salgınına tepkisini incelediği çalışmasında, 22 Ocak 2020'den 17 Nisan 2020'ye kadar olan zaman aralığında 64 ülkeden borsa getirileri, günlük doğrulanmış COVID-19 vaka ve ölüm verilerini kullanmıştır. Çalışmada, borsaların COVID-19 onaylı vakalardaki büyümeye olumsuz tepki verdiği, yani teyit edilen vaka sayısı arttıkça borsa getirilerinin düştüğü sonucuna ulaşılmıştır.

Chaouachi ve Chaouachi (2020), COVID-19 salgınının KSA borsası üzerindeki etkisini ARDL modeli ile 02 Mart-20 Mayıs 2020 tarihleri arası günlük verilerle analiz etmişlerdir. Ayrıca değişkenler arasındaki nedensellik ilişkisini Toda- Yamamoto nedensellik analizi ile test etmişlerdir. Çalışma sonucunda, COVID-19'un borsa üzerinde sadece uzun vadede olumsuz bir etkisi olduğunu belirlemişlerdir. Ayrıca nedensellik testi sonucunda COVID-19'dan borsaya doğru tek yönlü bir nedensellik olduğu tespit edilmiştir.

Ahmed (2020), COVID-19'un Pakistan hisse senetleri piyasasının performansı üzerindeki etkisini belirlemek için yaptığı çalışmasında, sadece COVID-19 iyileşen vakaların endeksin performansını etkilediğini belirlemiştir. Pozitif vakaların ve ölümlerin performansa etkisinin önemsiz olduğunu tespit etmiştir.

Waheed vd.(2020), COVID-19'un gelişmekte olan bir ülke olan Pakistan'ın borsas1 üzerindeki etkisine odaklandıkları çalışmalarında, KSE-100 endeksinin hisse senedi getirilerinde pozitif bir artış olduğu sonucuna ulaşmışlardır.

Kotishwar (2020), Covid-19 virüsünün borsalar üzerindeki etkisini araştırmak için, 11 Marttan- Nisan 2020'ye kadar virüsten en kötü etkilenen altı ülkenin (ABD, İspanya, Fransa, İtalya, Çin ve Hindistan) pozitif vaka büyümesini dikkate alarak yaptığı çalışmasında VECM 
modelini uygulamıştır. Sonuç olarak, Covid-19'un seçilen tüm ülkelerin hisse senedi endeksleri ile önemli düzeyde negatif ve uzun vadeli bir ilişkiye sahip olduğu görülmüştür.

He vd. (2020), COVID-19'un borsalar üzerindeki doğrudan etkilerini ve yayılmalarını inceledikleri çalışmalarında, geleneksel t-testleri ve non-parametrik Mann-Whitney testlerini kullanarak, Çin Halk Cumhuriyeti, İtalya, Güney Kore, Fransa, İspanya, Almanya, Japonya ve Amerika Birleşik Devletleri'ndeki borsalardan günlük getiri verilerini analiz etmişlerdir. Sonuç olarak, COVID-19'un etkilenen ülkelerin borsaları üzerinde olumsuz ancak kısa vadeli bir etkiye sahip olduğunu ve COVID-19'un hisse senedi piyasaları üzerindeki etkisinin Asya ülkeleri, Avrupa ve Amerika ülkeleri arasında çift yönlü yayılma etkileri olduğunu belirlemişlerdir.

Sansa (2020) Covid-19 salgınının Çin ve ABD'de finansal piyasaları üzerindeki etkisini 1-25 Mart tarihleri arasındaki veriler ile basit regresyon modelini kullanarak analiz etmiştir. Çalışma sonucunda Covid-19 salgını ile ilgili ülkelerin finans piyasaları arasında olumlu ve anlamlı bir ilişki olduğu tespit edilmiştir.

Topcu ve Gülal (2020), Covid-19'un gelişmekte olan borsalar üzerindeki etkisini incelediği çalışmasında, salgının gelişmekte olan borsalar üzerindeki olumsuz etkisinin kademeli olarak azaldığını ortaya koymuştur. Ayrıca salgının etkisinin en fazla yükselen Asya pazarlarında görüldüğü sonucuna ulaşmışlardır.

Liu vd. (2020) Japonya, Kore, Singapur, ABD, Almanya, İtalya ve İngiltere dahil olmak üzere Covid-19 salgınından etkilenen ülkelerin, salgının borsa endeksleri üzerindeki kısa vadeli etkisini incelemişlerdir. Sonuç olarak etkilenen ülke ve bölgelerdeki borsaların virüs salgını sonrasında hızla düştüğünü belirlemişlerdir. Asya kıtasındaki ülkelerin diğer ülkelere kıyasla daha fazla negatif anormal getiri yaşadığı tespit edilmiştir.

\section{VERİ SETİ VE METODOLOJİ}

Çalışmada, Covid-19 salgınının borsa üzerindeki etkilerini incelemek amacıyla, Borsa İstanbul (BIST) toplam işlem hacmi ve günlük doğrulanmış Covid-19 pozitif vaka sayıları 11 Mart-16 Haziran 2020 tarihleri arası günlük verilerle analize dahil edilmiştir. 11 Mart 2020'nin başlangıç tarihi olarak seçilmesinin nedeni, Türkiye'deki ilk COVID-19 vakasının tespit edilmesidir. Çalışmada kullanılan BIST toplam işlem hacmi verileri EVDS ( T.C. Merkez Bankası Elektronik Veri Dağıtım Sistemi)'den, Covid-19 günlük doğrulanmış vaka sayısı verileri ise Türkiye Cumhuriyeti Sağlık Bakanlığı'nın resmi web sitesinden (https://covid19.saglik.gov.tr/) elde edilmiştir. Değişkenler analize doğal logaritmaları alınarak dahil edilmiştir. COVID-19'un BIST üzerindeki etkisi ARDL yöntemiyle tahmin edilmiştir.

ARDL modeli, Pesaran ve Shin (1999) ve Pesaran vd. (2001) tarafından değişkenler arasındaki eşbütünleşme ilişkisinin belirlenmesi için geliş̧irilmiştir. ARDL yöntemi, literatürde kullanılan Engle ve Granger (1987), Johansen (1988) ve Johansen ve Juselius (1990) eşbütünleşme testlerine göre bir takım avantajlara sahiptir. ARDL testinin en önemli avantaj1, modelde kullanılacak değişkenlerin seviyede durağan ya da birinci farkta durağan olup olmamasına bağlı olmadan ARDL sınır testinin uygulanmasının mümkün olmasıdır. Bu sebeple sınır testini uygulamadan önce değişkenlerin durağanlık derecelerini 
belirlemeye gerek yoktur. Fakat ikinci farkta durağan değişkenlere ARDL modeli uygulanamaz. Bu nedenle değişkenlere birim kök testi sınaması yapılması gerekmektedir. İkinci olarak, kısıtlanmamış hata düzeltme modelinin (UECM) kullanılması, Engle-Granger eşbütünleşme testine (Engle Granger Cointegration test) göre daha iyi istatistiksel özelliklere sahip olmasını sağlamaktadır (Narayan ve Narayan, 2005,429). ARDL yaklaşımının diğer büyük avantajı, küçük örneklem büyüklügüne sahip çalışmalara uygulanabilmesidir. Engle \& Granger (1987) ve Johansen (1988) eşbütünleşme yöntemlerine göre küçük örneklem büyüklükleri için daha güvenilir sonuçlar elde edilmektedir (Narayan ve Smyth, 2005:103). Çalışmada ARDL modeli ile eşbütünleşme ilişkisinin belirlemek için aşağıdaki eşitlikler kullanılmaktadır.

$$
\ln (\mathrm{BISTIH})=\mathrm{a}_{0}+\ln (\text { COVID }-19)+\varepsilon_{i}
$$

Çalışmada doğrusal tahmin denklemi (1) nolu eşitlikte gösterilmiştir. ARDL sınır testi için kısıtsız hata düzeltme modeli (2) nolu denklemde oluşturulmuştur.

$$
\begin{aligned}
& \Delta \ln (\mathrm{BISTIH})_{\mathrm{t}}=\mathrm{a}_{0}+\sum_{i=1}^{m} a_{1 i} \Delta \ln (\mathrm{BISTIH})_{t-i}+\sum_{i=0}^{m} a_{2 i} \Delta \ln (\operatorname{COVID}-19)_{t-i}+a_{1} \\
& \ln (\mathrm{BISTIH})_{t-1}+a_{2} \ln (\text { COVID }-19)_{t-1}+\varepsilon_{i}
\end{aligned}
$$

Eşitlikte yer alan $\Delta$ fark operatörünü, a sabit terimi, $\varepsilon_{\tilde{i}}$ ise hata terimini ifade etmektedir. (2) nolu denklem tahmin edildikten sonra uzun dönemli bir ilişkinin varlığının test edilmesinde Wald testi (Wald test) kullanılmaktadır. Bu testin hipotezleri ise şu şekildedir;

$$
\begin{aligned}
& H_{0}: \delta_{1}=\delta_{2}=0 \\
& H_{0}: \delta_{1} \neq \delta_{2} \neq 0
\end{aligned}
$$

Uzun dönemli ilişkinin analizi için hesaplanan F istatistik değeri, Pesaran ve Smith'in (2001) çalışmalarında asimptotik olarak türetilen anlamlılık düzeyleri ile karşılaştırılmaktadır. $\mathrm{Bu}$ çalışmada değişkenlerin $\mathrm{I}(0)$ ve $\mathrm{I}(1)$ olup olmamasına göre alt ve üst değerler verilmiştir. Eğer $\mathrm{F}$ istatistiği kritik değerin altında ise eş bütünleşme ilişkisinin bulunmadığı, kritik değerin üstünde ise eş bütünleşme ilişkisinin bulunduğu sonucuna ulaşılmaktadır. Eğer bulunan $\mathrm{F}$ istatistik değeri alt ve üst değer arasında kalırsa, bu durumda eş bütünleşmenin olup olmadığına dair bir yorum yapılamaz (Akel ve Gazel, 2014: 31). ARDL testi ile değişkenler arasında uzun dönemli bir ilişki belirlenmişse uzun dönem katsayılarının tahminine geçilir. Uzun dönem katsayılarının tahmini için oluşturulan (4) nolu denklemde ARDL $(m, n)$ modeli oluşturulmuştur.

$$
\ln (\mathrm{BISTIH})_{\mathrm{t}}=\mathrm{a}_{0}+\sum_{i=1}^{m} a_{1 i} \ln (\mathrm{BISTIH})_{t-i}+\sum_{i=0}^{n} a_{2 i} \ln (\mathrm{COVID}-19)_{t-i}+\varepsilon_{i}
$$

Uzun dönemli ilişski katsayıları belirlendikten sonra modelin tanısal (diagnostik) testleri kontrol edilir ve modelin uygunluğuna karar verilir. Ayrıca CUSUM ve CUSUMSQ testlerinden yararlanılarak ARDL modelindeki değişkenlerin istikrarı kontrol edilebilir. Değişkenler arasında kısa dönemli ilişkilerin belirlenmesinde ARDL' ye dayanan bir hata düzeltme modeli (5) nolu denklemde tahmin edilmektedir.

$$
\begin{aligned}
& \Delta \ln (\mathrm{BISTIH})_{\mathrm{t}}=\mathrm{a}_{0}+\sum_{i=1}^{m} a_{1 i} \Delta \ln (\mathrm{BISTIH})_{t-i}+\sum_{i=0}^{n} a_{2 i} \Delta \ln (\mathrm{COVID}-19)_{t-i}+a_{3} \\
& \mathrm{ECM}_{t-1}+\varepsilon_{i}
\end{aligned}
$$


(5) nolu denklemde $E C \mathrm{M}_{t-1}$ hata düzeltme terimidir. Hata düzeltme katsayıs1, değişkenler arasında uzun dönem ilişkisinin elde edildiği modelin kalıntılarının bir gecikmeli değerini ifade etmektedir. ECM ifadesinin katsayısı kısa dönemde meydana gelen bir şokun etkisinin ne kadarının uzun dönemde ortadan kalkacağını göstermektedir (Ergen ve Yavuz, 2017: 88).

\section{AMPIRIK BULGULAR}

Değişkenlerin durağanlığını test etmek için Artırılmış Dickey-Fuller (Augmented Dickey-Fuller - ADF) ve Philips-Perron birim kök testi (PP) kullanılmıştır. Tablo 1'de birim kök testi sonuçları görülmektedir. Değişkenlerin durağanlığı, ARDL modelini uygulamadan önce, herhangi bir serinin ikinci farkta durağan olmadığının kontrol edilmesi açısından önemlidir. Her iki test sonucu da ARDL sınır testinin uygulanabileceğini göstermiştir. Çünkü herhangi bir değişken ikinci farkta durağan değildir. ADF ve PP birim kök testleri bulgularına göre, her iki değişkeninde düzeyde durağan olduğu sonucuna ulaşılmıştır.

Tablo 1. ADF ve PP Birim Kök Testi Sonuçları

\begin{tabular}{|c|c|c|c|c|}
\hline & \multicolumn{2}{|c|}{$\mathrm{ADF}$} & \multicolumn{2}{|c|}{$\mathrm{PP}$} \\
\hline & \multicolumn{2}{|c|}{ Düzey } & \multicolumn{2}{|c|}{ 1. Fark } \\
\hline Değişkenler & $\begin{array}{l}\text { Sabit } \\
\text { t-Stat }\end{array}$ & $\begin{array}{l}\text { Sabit ve Trend } \\
\text { t-Stat }\end{array}$ & $\begin{array}{l}\text { Sabit } \\
\text { t-Stat }\end{array}$ & $\begin{array}{l}\text { Sabit ve Trend } \\
\text { t-Stat }\end{array}$ \\
\hline LNBISTIH & $-1,77218$ & $-5,64733 * * *$ & $-2,70419 *$ & $-5,64733 * * *$ \\
\hline LNCOVID-19 & $-3,35598 * *$ & $-3,29755^{*}$ & $-6,10034^{* * *}$ & $-6,90095 * * *$ \\
\hline \multicolumn{5}{|c|}{ Birinci Fark } \\
\hline LNBISTIH & $-8,49635 * * *$ & $-8,45066^{* * *}$ & $-30,2869 * * *$ & $-28,73820 * * *$ \\
\hline LNCOVID-19 & $-40,8748 * * *$ & $-27,34185 * * *$ & $-3,66991 * * *$ & $-5,31448 * * *$ \\
\hline Kritik Değerler & Sabit & Sabit ve Trend & & \\
\hline $1 \%$ & $-3,5332$ & $-4,09661$ & & \\
\hline $5 \%$ & $-2,9062$ & $-3,47628$ & & \\
\hline $10 \%$ & $-2,5906$ & $-3,16561$ & & \\
\hline
\end{tabular}

“***” \%1, “**” \%5 ve “*” \%10 anlam düzeyinde durağan olan değişkenleri göstermektedir.

ARDL modelinde ilk önce bağımlı ve bağımsız değişkenler için uygun gecikme uzunluğunun belirlenmesi gerekir. AIC (Akaike Information Criterion- Akaike Bilgi Kriteri), SC (Schwarz Criterion) ve HQ (Hannan-Quinn Criterion) zaman serisi verilerinde iyi bilinen gecikme seçimi yaklaşımlarıdır ve çoğunlukla gecikme uzunluğu seçimi için kullanılırlar. Modelin optimum gecikme uzunluğunu belirlemek için AIC kullanılmıştır. En küçük AIC değerine karşılık gelen ARDL $(1,1)$ modeli en uygun model olarak seçilmiştir. Şekil 1'de en iyi 20 AIC modelini görülmektedir. Daha sonra ARDL $(1,1)$ modeli tahmin edilmiş ve modele ilişkin tanısal test istatistikleri tablo 2'de verilmiştir. 
Akaike Bilgi Kriteri (En İyi 20 Model)

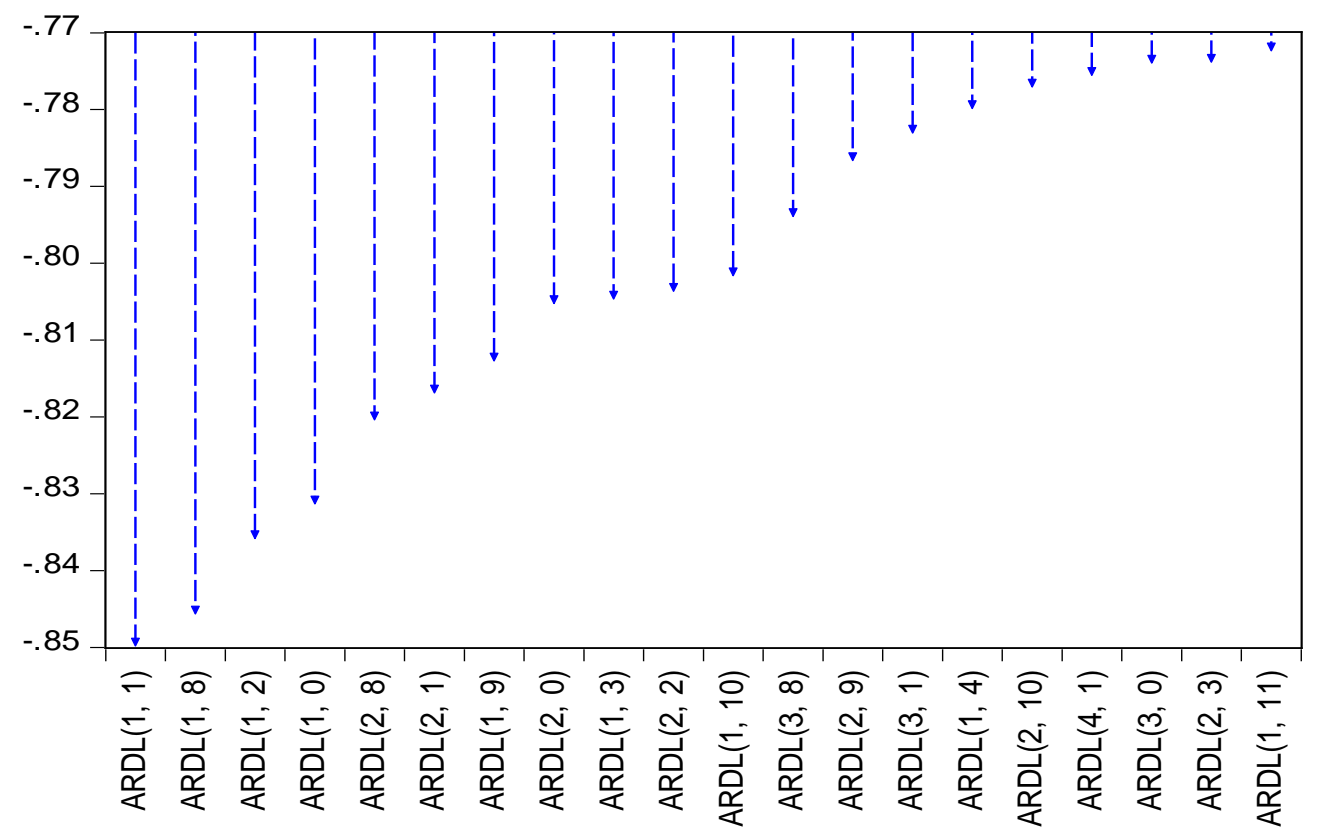

Şekil 1. Akaike Bilgi Kriteri(Akaike Information Criterion-AIC) (En İyi 20 Model)

Tablo 2'deki tanısal test sonuçlarına bakıldığında modelin otokorelasyon (BreuschGodfrey Otokorelasyon LM testi) ve değişen varyans (Otoregresif koşullu değişen varyansAutoregressive Conditional Heteroscedasticity-ARCH) sorunu içermediği, normal dağılım (Jarquera-Bera testi) gösterdiği ve model kurma hatasının (Ramsey Reset Testi) bulunmadığı görülmektedir.

Tablo 2. ARDL $(1,1)$ Tanısal Test Bulguları

\begin{tabular}{l|c}
\hline \multicolumn{1}{c|}{ Tanısal Testler } & Ístatistikler \\
\hline R2 & 0.67 \\
Adjusted R2 & 0.66 \\
F_istatistiği & $45.287(0.0000)$ \\
Breusch-Godfrey LM testi & F-istatistiği $=1.4229(0.2486)$ \\
ARCH Değişen Varyans testi & F-istatistiği $=1.6439(0.1879)$ \\
Jarquera-Bera Testi & $1.5835(0.4530)$ \\
Ramsey Reset Testi & F-istatistiği $=3.7071(0.0586)$ \\
\hline
\end{tabular}

Not: Parantez içindeki değerler olasılık değerlerini ifade etmektedir.

Tanısal test sonuçlarına göre modelin uygun ve tutarlı olduğunu belirledikten sonra, değişkenler arasında uzun dönemli ilişkinin varlığını test etmek amacıyla ARDL sınır testi uygulanmıştır. Tablo 3'de ARDL $(1,1)$ sınır testi sonuçları sunulmuştur. 
Tablo 3. ARDL (1,1) Sinır Testi Sonuçları

\begin{tabular}{ccc} 
Test İstatistiği & Değer & \\
\hline F_istatistiği & 16,56105 & \\
\hline & Kritik Değer Sinırları & $\mathrm{I}(1)$ \\
\hline Önem Düzeyi & $\mathrm{I}(0)$ & 32.234 \\
$10 \%$ & 4.125 & 5.915 \\
$5 \%$ & 5.055 & 8.405 \\
$1 \%$ & 42.917 & \\
\hline
\end{tabular}

Modelin Tablo 3' deki F istatistiği sonuçları, değişkenler arasında uzun vadeli eş bütünleşme ilişkisi olduğunu doğrulamaktadır. ARDL sınır testinin sonuçları (Tablo 3), Fistatistiksel değerinin $(16,56105) \% 1, \% 5$ ve \% 10 kritik düzey eşiklerinin üzerinde olduğunu göstermektedir. Bu nedenle, $\mathrm{H}_{0}$ hipotezi reddedilir ve $\mathrm{H}_{1}$ hipotezi kabul edilir; yani değiş̧kenlerin uzun dönemli ilişkisi olduğu ispatlanmıştır ve ARDL $(1,1)$ modeli için uzun dönem ilişkisini yansıtan parametrelerin tahminine geçilmiştir. Tablo 4'de uzun dönem tahmin sonuçları verilmiştir.

Tablo 4. ARDL $(1,1)$ Modeli Uzun Dönem Tahminleri

\begin{tabular}{ccll}
\hline \multicolumn{4}{c}{ Bağımlı Değişken lnBISTIH } \\
\hline Bağımsız Değişkenler & Katsayı & t-istatistiği & Olasılık \\
$\operatorname{lnCOVID-19}$ & 0.0463 & 2.2463 & 0.0281 \\
C & 9.3042 & 5.7069 & 0.0000 \\
\hline
\end{tabular}

Tablo 4'e göre, lnCOVID-19 ve lnBISTIH değişkenlerinin uzun dönem elastikiyet katsayıs1 0.0463 ve \%5 önem düzeyinde istatistiksel olarak anlamlıdır. Değişkenler arasında uzun dönemde pozitif yönlü bir ilişki olduğu görülmektedir. LnCOVID-19'da meydana gelecek \%1'lik bir değişim lnBISTIH'de \%0.046'lık bir değişime sebep olacaktır.

ARDL modelinde kullanılan değişkenlerin katsayılarının istikrarlılığının ölçülmesinde, diğer bir deyişle yapısal kırılmanın olup olmadığının belirlenmesinde Brown vd. (1975) tarafından geliştirilen CUSUM (Ardışık hataların kümülatif toplamı- Cumulative Sum of the recursive residuals) ve CUSUMQ (Ardışık hata karelerinin kümülatif toplamı-CUSUM of squares) testleri kullanılmaktadır. Hesaplanan testler Şekil 2'de gösterilmiştir. 


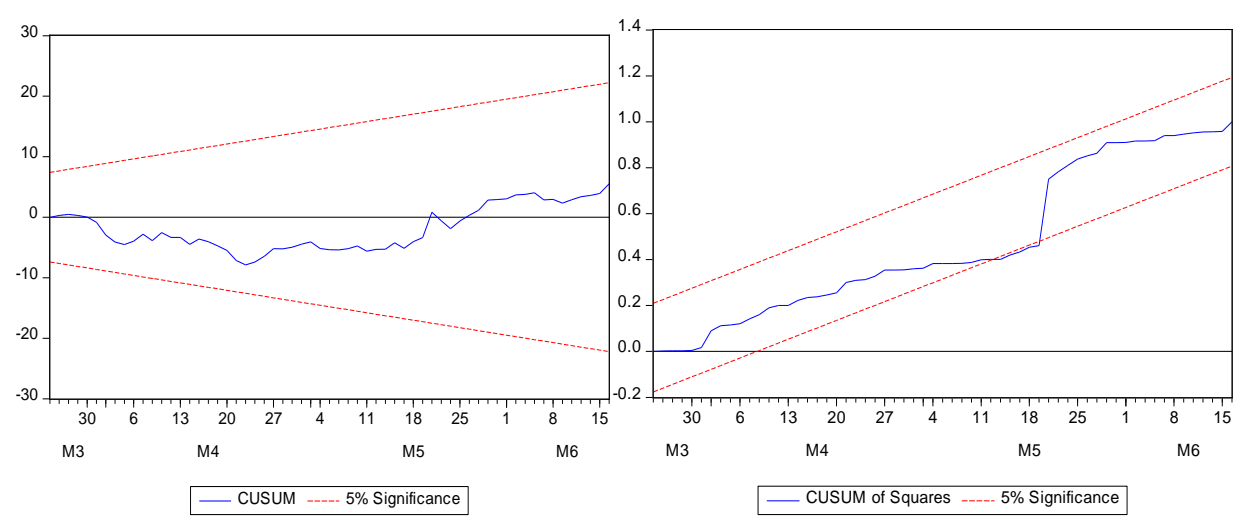

Şekil 2. CUSUM ve CUSUMQ Grafikleri

CUSUM ve CUSUMQ istatistikleri, \% 5 anlamlılık kritik sınırına göre çizilir. Bahmani-Oskooee ve Wing NG'ye (2002) göre, eğer bu istatistikler \% 5 önem seviyesinin kritik sınırı içinde kalırsa, ARDL modelindeki katsayıların istikrarlı olduğu kabul edilir. Şekil 2 incelendiğinde, \%5 anlamlılık düzeyinde kritik sınırların dışına çıkan gözlem bulunmadığ yani herhangi bir yapısal kırılmanın olmadığı görülmektedir. ARDL sınır testine göre hesaplanan uzun dönem katsayıların istikrarlı olduğu anlaşılmaktadır.

Değişkenler arasındaki kısa dönem ilişkilerinin tahmini için ARDL Hata Düzeltme Modeli tahmin edilmiş ve kısa dönem tahmin sonuçları Tablo 5'de verilmiştir.

Tablo 5. ARDL $(1,1)$ Modeli Kısa Dönem Tahminleri

\begin{tabular}{clcc}
\hline & \multicolumn{4}{c}{ Bağımlı Değişken lnBISTIH } & \\
\hline Bağımsız Değişkenler & Katsayı & t-istatistiği & Olasılık \\
lnCOVID-19 & -0.1816 & -3.2702 & 0.0017 \\
C & 9.3042 & 5.8169 & 0.0000 \\
ECM & -0.5718 & -5.7993 & 0.0000 \\
\hline
\end{tabular}

Hata Düzeltme Modeli’nden elde edilen sonuçlara göre, lnCOVID-19 ve $\operatorname{lnBISTIH}$ değişkenleri arasında negatif yönlü ve istatistiksel olarak anlamlı bir ilişki olduğu tespit edilmiştir. Yani günlük COVID-19' vaka sayısında meydana gelecek \%1'lik bir artış BIST işlem hacminde \% $0.18^{\prime}$ lik bir düşüşe yol açmaktadır. Hata düzeltme katsayısı negatiftir ve istatistiksel olarak anlamlıdır. Başka bir ifade ile kısa dönem şoklarını takiben uzun dönem dengesinde meydana gelecek sapmaların bir dönem sonrasında \% 57'sinin giderilebildiğini göstermektedir.

\section{SONUÇ}

Küresel bir sorun olan Covid-19 pandemisinin halk sağlı̆̆1 ve ekonomi alanında ciddi etkileri mevcuttur. Pandemi sürecinde hükümetlerin uyguladığı çeşitli kısıtlama ve yasakların 
ekonomiye büyük bir zarar verdiği aşikârdır. Bu bağlamda çalışmada, ARDL sınır testi yöntemiyle 11 Mart-16 Haziran 2020 tarihleri arasında koronavirüsün yayılmasının borsa işlem hacmi üzerindeki kısa ve uzun vadeli ekonomik etkileri analiz edilmiştir. Çalışma bu yönüyle gelişmekte olan bir ülkenin hisse senedi piyasası işlem hacminin, bu süreçten nasıl etkilendiğini ortaya koyması açısından literatüre katkı sağlamaktadır. Çalışmada bağımlı değişken olarak BIST toplam işlem hacmi ve bağımsız değişken olarak günlük doğrulanmış COVID-19 pozitif vaka sayıları doğal logaritmaları alınarak analize dahil edilmiştir. Çalışma sonucunda COVID-19 teyitli vakalar ile borsa işlem hacmi arasında kısa vadede negatif ve istatistiksel olarak \%1 önem düzeyinde anlamlı bir ilişki olduğu belirlenmiş̧ir. Bu durumda Covid-19 vakalarındaki artışın kısa vadede borsayı olumsuz etkilediği söylenebilir. Uzun dönem ilişki sonuçlarına bakıldığında ise değişkenler arasında \%5 önem düzeyinde istatistiksel olarak anlamlı ve pozitif bir ilişki olduğu tespit edilmiştir. Uzun dönemde bu olumlu etkinin görülmesinde faizlerdeki gerilemenin ardından getiri arayışına giren yatırımcılar ve Türkiye'nin salgın döneminde sağlık alanındaki başarıları ile ekonomi alanındaki proaktif adımlarının önemli rol oynadığı söylenebilir.

Türkiye'deki ilk pozitif vaka sayısının analize başlangıç tarihi olarak alınması çalışmanın kısıtını oluşturmaktadır. Çünkü finansal piyasaların gösterdiği tepki, sadece Türkiye'deki vakaların değil, dünyada artan vaka sayıları ve bunun sonucu oluşan korku, panik ve risk algısının da bir sonucudur. Küresel piyasaların etkileşimi göz önüne alındığında, konuyla ilgili bundan sonra yapılacak çalışmalarda Dünya'da ilk vaka, Amerika'da ilk vaka ve Avrupa'da ilk vaka tarihleri baz alınarak analiz genişletilebilir.

\section{KAYNAKLAR}

Ahmed, Sheharyar (2020), "Impact of Covid-19 on Performance of Pakistan Stock Exchange”, Preprints, 2020070083 (Doi: 10.20944/Preprints 20 2007. 0083.V1), pp. $1-12$.

Akel, Veli - Gazel, Sümeyra (2014), "Döviz Kurları ile Bıst Sanayi Endeksi Arasındaki Eşbütünleşme İlişkisi: Bir Ardl Sınır Testi Yaklaşımı”, Erciyes Üniversitesi İktisadi ve İdari Bilimler Fakültesi Dergisi, Sayı: 44, ss. 23-41

Ashraf, Badar Nadeem (2020), “Stock Markets' Reaction to Covid-19: Cases or Fatalities?”, Research in International Business and Finance, 54, pp. 1-7.

Bahmani-Oskooee, Mohsen - Wing Ng, Raymond Chi (2002), "Long-Run Demand for Money in Hong Kong: An Application of the Ardl Model”, International Journal of Business and Economics, 1(2), pp. 147-155.

Brown, Robert L - Durbin, James - Evans, Jonathan M. (1975), “Tech-Niques for Testing the Constancy of Regression Relationships over Time”, Journal of The Royal Statistical Society, 37(2), pp. 149-192. 
Chaouachi, Maroua. - Chaouachi, Slim (2020), "Current Covid-19 Impact on Saudi Stock Market: Evidence from an Ardl Model”, International Journal of Accounting, Finance, Auditing, Management and Economics, 1(1), pp.1-13.

Engle, Robert F. - Granger, C.W.J. (1987), “Co-İntegration and Error Correction: Representation, Estimation, and Testing”, Econometrica: Journal of The Econometric Society, Vol 55, No 2, pp. 251-276.

Ergen, Eren - Yavuz, Ersin (2017), "Büyüme ile Harcama Arasındaki İlişkinin Ardl EşBütünleşme ve Granger Nedensellik Testleri ile Analizi: Türkiye Üzerine Kanıtlar”, Uluslararası Yönetim İktisat ve İşletme Dergisi, Icmeb17 Özel Sayısı, ss.84-92.

He, Qing - Liu, Junyi - Wang, Sizhu - Yu, Jishuang (2020), “The Impact of Covid-19 on Stock Markets”, Economic and Political Studies, 8(3), pp. 275-288, Doi: 10.1080/20954816.2020.1757570

Johansen, Soren (1988), "Statistical Analysis of Cointegration Vectors”, Journal of Economic Dynamics and Control, 12(2-3), pp. 231-254.

Johansen, Soren - Juselius, Katarina (1990), “Some Structural Hypotheses in A Multivariate Cointegration Analysis of the Purchasing Power Parity and The Uncovered Interest Parity for Uk”, Discussion Papers, University of Copenhagen, No 90-05.

Kotishwar, A. (2020), “Impact of Covid-19 Pandemic on Stock Market with Reference to Select Countries - A Study", Academy of Accounting and Financial Studies Journal, Volume 24, Issue 4, pp. 1-9.

Liu, Hai Yue - Manzoor, Agsa - Wang, Cang Yu - Zhang, Lei - Manzoor, Zaira (2020), “The Covid-19 Outbreak and Affected Countries Stock Markets Response”, Environmental Research and Public Health,17, pp.1-19

Narayan, Paresh Kumar - Smyth, Russell (2005), "Trade Liberalization and Economic Growth in Fiji. An Empirical Assessment Using the Ardl Approach”, Journal of The Asia Pacific Economy, 10(1), pp. 96-115.

Narayan, Paresh Kumar - Narayan, Seema (2005), "Estimating Income and Price Elasticities of Imports for Fiji in A Cointegration Framework”, Economic Modelling, 22, pp. 423438.

Öztürk, Özcan- Şişman, Muhammet Y. - Uslu, Hakan - Çitak, Ferhat (2020), "Effect of Covid-19 Outbreak on Turkish Stock Market: A Sectoral-Level Analysis”, Hitit University Journal of Social Sciences Institute, 13(1), pp.56- 68.

Pesaran, M. Hashem - Shin, Yongcheol (1999), “An Autoregressive Distributed Lag Modelling Approach to Cointegration Analysis”, Econometrics and Economic Theory in The 20th Century: The Ragnar Frish Centennial Symposium. Ed. / Steinar Strom. Cambridge: Cambridge University Press”, pp. 371-413. 
Pesaran, M. Hashem - Shin, Yongcheol - Smith, Richard J. (2001), "Bounds Testing Approaches to The Analysis of Level Relationships”, Journal of Applied Econometrics, Vol 16, Issue 3, pp. 289-326.

Sansa, Nuhu A. (2020), “The Impact of the Covid - 19 on The Financial Markets: Evidence from China and Usa”, Electronic Research Journal of Social Sciences and Humanities, Vol 2, Issue I, pp. 29-39.

Topcu, Mert - Gulal, Ömer Serkan (2020), “The Impact of Covid-19 on Emerging Stock Markets”, Finance Research Letters, 36, pp.1-5.

Waheed, Rida - Sarwar, Suleman - Sarwar Sahar - Khan, Muhammad Kaleem (2020), “The Impact of Covid-19 on Karachi Stock Exchange: Quantile-On-Quantile Approach Using Secondary and Predicted Data”, Journal of Public Affairs, E2290. Https://Doi.Org/10.1002/Pa.2290

Yan, Binxin - Stuart, Logan - Tu, Andy - Zhang, Qingquan (2020), “Analysis of The Effect of Covid-19 on The Stock Market and Investing Strategies", Ssrn: Https://Ssrn.Com/Abstract=3563380 Or Http://Dx.Doi.Org/10.2139/Ssrn.356338 0

https://www.tcmb.gov.tr , (Erişim Tarihi: 20.06.2020).

https://ourworldindata.org (Erişim Tarihi: 20.06.2020).

https://covid19.saglik.gov.tr/ (Erişim Tarihi: 20.06.2020).

https://evds2.tcmb.gov.tr/ (Erişim Tarihi: 20.06.2020). 